\title{
Pediatric Nurse Specialist
}

National Cancer Institute

\section{Source}

National Cancer Institute. Pediatric Nurse Specialist. NCI Thesaurus. Code C20843.

The clinical specialist in pediatric nursing is a graduate-prepared clinician and child and family advocate. Within the scope of pediatric nursing practice the child and family are considered the client. Clinical specialists demonstrate an in-depth understanding of complex pediatric health care by eng aging in education, case management, expert clinical practice, consultation, research and administration. Change and systems theory are utilized to develop interventions to manage and improve patient care. Clinical specialists in pediatric nursing practice across the trajectory of care in settings which include primary, acute, community, or rehabilitation. (ANCC) 